\title{
ANTHOCYANINS, CAROTENOIDS AND ANTIOXIDANT ACTIVITY OF COLOURED COMMERCIALLY AVAILABLE JUICES
}

\author{
ANDREA BUNEA ${ }^{a}$, SANDA ANDREI ${ }^{a,}$, , CRISTINA EL-MAHDI ${ }^{b}$, \\ ALINA CUCERDEAN", FLORIN DUMITRU BORA ${ }^{d}$, \\ ZORITA DIACONEASA ${ }^{a}$, ADELA PINTEA $^{a}$
}

\begin{abstract}
The phytochemical composition of apple, cranberry, pomegranate, carrot, and beetroot juices was determined in terms of carotenoids, anthocyanins, betalains and ascorbic acid concentration. Antioxidant potential of these beverages was also assessed using the colorimetric DPPH radical scavenging assay. The results showed that pasteurized and unpasteurized carrot and apple juices contain significant amount of $\beta$-carotene and cis- $\beta$ carotene. High total betalain content was observed in beetroot juice. Major anthocyanins detected in cranberry and pomegranate juices were glycosides of cyanidin, malvidin, and delphinidin. Notable ascorbic acid content and antioxidant potential were observed in unprocessed carrot juices, while beetroot juice exhibited the highest percentage of free radical inhibition.
\end{abstract}

Keywords: juices, ascorbic acid, carotenoids, anthocyanins, antioxidant activity

a Department of Biochemistry, University of Agricultural Sciences and Veterinary Medicine, Cluj-Napoca

${ }^{\mathrm{b}}$ Department of Fundamental Science, University of Agricultural Sciences and Veterinary Medicine, Cluj-Napoca

${ }^{c}$ Agrico Research, Bant, Holand

d Department of Physico-Chemistry and Biochemistry, Research Station for Viticulture and Enology Târgu Bujor

*Corresponding author: sandrei@usamvcluj.ro 


\section{INTRODUCTION}

A growing interest in consumption of fruits and vegetables has been recently observed, due to their nutritional and medicinal value. This effectiveness is thought to be mainly related to bioactive compounds present in the plants, such as carotenoids, betalains, anthocyanins, flavonoids, and ascorbic acid.

In the last few years, many reviews were published focusing on the chemistry, bioavailability, and health and nutrition benefits of carotenoids $[1,2]$. So far the most analyzed and studied carotenoids are $\beta$-carotene, lutein, and zeaxanthin. $\beta$-carotene has high provitamin $A$ activity, while lutein and zeaxanthin play an important role in the prevention of several blinding disorders by absorbing blue light that enters the human eye [3]. Carrots are the most important source of $\beta$-carotene in the diet, along with green leafy vegetables. Betanin, the most abundant betacyanin pigment in beetroot, have been found to have great antioxidant activity and it is also effective in preventing lipid peroxidation [4]. Other class of phenolic compounds found in fruits, berries or vegetable are anthocyanins. From chemical point of view, they are glycosides of anthocyanidins and it is currently thought that only the following six are of relevance to the human diet (cyanidin, delphinidin, malvidin, pelargonidin, peonidin, petunidin) [5].

Several observational and randomized controlled studies demonstrated that fruit-based diets are important factor for reducing the burden of noncommunicable diseases. Diets rich in anthocyanins promote the lowering of cardiovascular disease and are promising candidates in developing antiobesity therapies $[5,6]$. They also bear anti-inflammatory and antimicrobial properties, limit the oxidative stress, and contribute to cellular signaling by interacting with a wide spectrum of molecular targets $[7,8]$.

Low plasma ascorbic acid content is associated with increased risk of stroke, especially among hypertensive and overweight men aged 42-60 years [9]. Moreover, ascorbic acid is a promising anti-cancer agent [10] and is likely to reduce the risk of coronary heart disease [11].

Beetroot juice protect against cold symptoms in health during periods of psychological stress and suggest particular benefits in asthma [12]. Cranberry based products bear high antioxidant and antiradical properties [13] and might improve augmentation index in obese men [20]. Clinical trials have demonstrated that pomegranate juice has benefit effect on polycystic ovarian syndrome [14], blood pressure and lipid profile [15, 16], and increases glutathione activity reducing lipid and protein oxidation [17]. Pomegranate is also important in nanotechnology for biosynthesizing different nanoparticles [18]. 
Composition, bioavailability, and antioxidant activity of phytochemicals are significantly influenced by plant processing and other post-harvest technologies [19-24]. Thus, these steps should be designed with caution in order to preserve or enhance the quality of products. When fruits and vegetables are made into fresh-squeezed juices, several bacteria might be present in the final product. Pasteurization is the most common way to remove bacteria and other potentially harmful microorganisms [25], however, it usually leads to degradation of biologically active compounds. Ultrasound treatment might be a reliable, innovative alternative of pasteurization that could effectively improve the health-related compounds and other quality parameters of fruit juices [26-30].

Herein, we assessed the carotenoid content of several, unpasteurized and pasteurized carrot and apple juices and anthocyanins respectively betalains content of commercially available beetroot, cranberry, and pomegranate juices. Ascorbic acid content was evaluated using titrimetric method and antioxidant potential of the samples were determined through spectrophotometric methods.

\section{RESULTS AND DISCUSSION}

\section{Carotenoid content of the carrot and apple juices}

Carotenoids were extracted, underwent a saponification process and were separated and analyzed by HPLC (Figure 1 and Experimental section). In all tested samples, $\beta$-carotene and cis- $\beta$-carotene were identified as the major carotene compounds (Table 1). In accordance with the literature data [2], significantly higher concentrations of total carotenoids were observed in carrot juice samples as compared to apple juices. More surprisingly, no carotenoid compound was identified in commercial apple juice.

Similar concentrations of total carotenoids were obtained in samples of the same species (50.00-54.00 mg/100g in carrot samples, $24.00 \mathrm{mg} / 100 \mathrm{~g}$ and $29.00 \mathrm{mg} / 100 \mathrm{~g}$ in apple samples) (Table 1). Apparently, pasteurization process has no significant adverse effect on the total carotenoid concentration in carrot and apple samples, but it might induce or accelerate several isomerization reactions. Naturally, $\beta$-carotene is found as all-trans isomers in plants. However, these isomers are very unstable and can easily undergo transformation into cis-isomers when exposed to heat and light [31]. It has been demonstrated that commercial carrot juices might contain from $4 \%$ to $17 \%$ cis- $\beta$-carotene [32]. Marx et al have also revealed that $13-c i s-\beta$-carotene was formed during the pasteurization and sterilization of carrot juice [25]. Similar conclusions were obtained by Chen et al, who reported $62.5 \mu \mathrm{g} / \mathrm{mL} \beta$ carotene together with $1.1-3.4 \mu \mathrm{g} / \mathrm{mL}$ cis-isomer for untreated carrot juice. 
When different pasteurization conditions were applied (temperature up to $121^{\circ} \mathrm{C}$ ), the $\beta$-carotene content decreased steadily along with increasing temperature and heating time, while cis-isomers increased significantly [33]. In accordance with these findings, we also observed higher cis- $\beta$-carotene concentrations in all tested sample as compared to $\beta$-carotene content.

Nevertheless, significant $(P<0.05)$ increases in total carotenoids were observed in thermo-sonicated carrot and apple juices as compared to non-sonicated samples (1.37 and $1.55 \mu \mathrm{g} / \mathrm{mL}$, respectively, compared to $1.22 \mu \mathrm{g} / \mathrm{mL})[29,34]$.

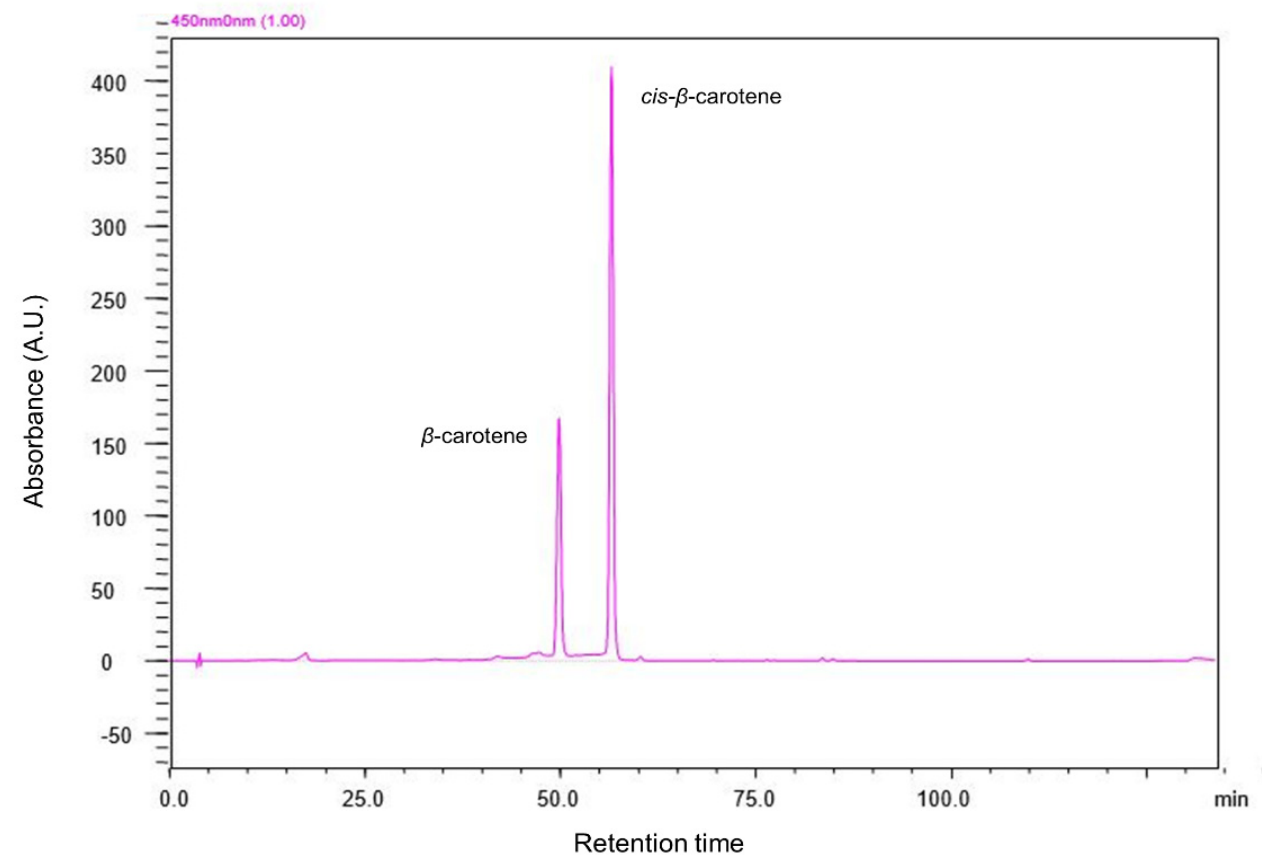

Figure 1. Carotenoids separation for saponified sample of unfiltered carrot juice

Table 1. Carotenoid content of carrot and apple juices

\begin{tabular}{lccc}
\hline Sample & $\begin{array}{c}\text { Total carotenoids (士SD) } \\
\mathbf{m g} / \mathbf{1 0 0 g}\end{array}$ & $\begin{array}{c}\boldsymbol{\beta} \text {-Carotene } \\
\mathbf{m g} / \mathbf{1 0 0 g}\end{array}$ & $\begin{array}{c}\text { cis- } \boldsymbol{\beta} \text {-Carotene } \\
\mathbf{~ m g / 1 0 0 g}\end{array}$ \\
\hline Unfiltered carrot juice & $54.00 \pm 6.34^{\mathrm{a}}$ & 16.74 & 37.26 \\
Pasteurized carrot juice & $50.00 \pm 5.22^{\mathrm{a}}$ & 15.5 & 34.5 \\
Unpasteurized carrot juice & $53.40 \pm 4.13^{\mathrm{a}}$ & 16.55 & 36.84 \\
Commercial apple juice & - & - & - \\
Pasteurized apple juice & $24.00 \pm 3.56^{\mathrm{b}}$ & 7.44 & 16.56 \\
Unpasteurized apple juice & $29.00 \pm 2.87^{\mathrm{b}}$ & 8.99 & 20.01 \\
\hline
\end{tabular}

SD, standard deviation. Different letters within a column denote significant differences $(P<0.05)$. 


\section{Anthocyanins content of red juices}

Anthocyanins from beetroot, cranberry, and pomegranate juices were extracted with acidified methanol and further analyzed by HPLC-DAD or HPLC-ESI-MS techniques (Figure 2 and Experimental Section).

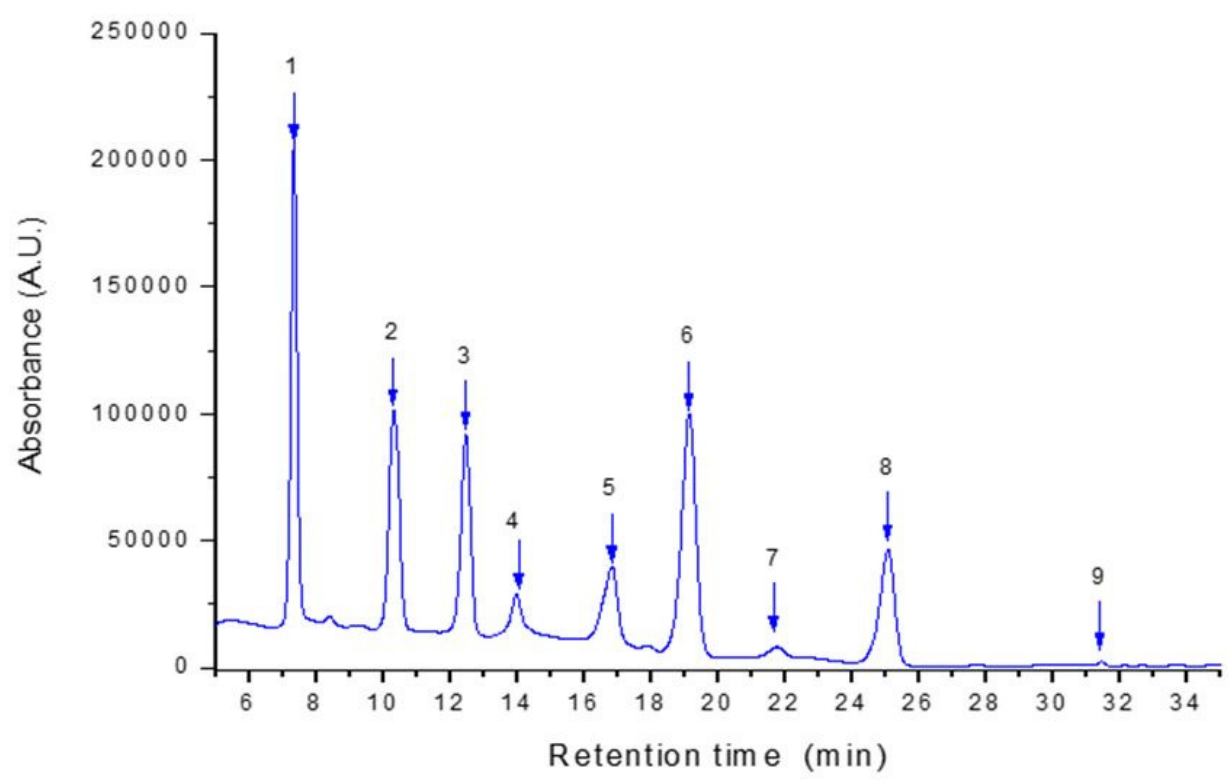

Figure 2. Illustrative HPLC chromatogram of the anthocyanins from cranberry juice. Peak assigment: 1 . delphinidin 3-O-galactoside; 2 . delphinidin 3-O-glucoside; 3. cyanidin 3-O-galactoside; 4. delphinidin 3-O-arabinoside; 5. cyanidin 3-O-glucoside; 6. petunidin 3-O-galactoside; 7. cyanidin 3-O-arabinoside; 8. peonidin-3-O-galactoside; 9. petunidin 3-O-arabinoside

In beetroot juice, betanin and isobetanin were identified as the major components ( $>80 \%$ of total concentration). Betanidin and neo-betanidin-5glucoside were also detected (Table 2). These findings are in accordance with those reported in other studies [35]. In red beet concentrate, betanin and isobetanin were detected in similar quantity $(40.6 \%$ and $40.2 \%$, respectively of total betalains), while betanidin yielded $8.4 \%$ and neo-betadinin-5glucoside $3.9 \%$ [36]. The two latter compounds are likely to result from thermal degradation of beetroot juice [37].

Total betacyanin content obtained in this study was $656.21 \mathrm{mg} / 100 \mathrm{~mL}$. Wruss et al determined the total betalain content of beetroot juices prepared from 7 varieties. They results shows concentrations which varied between 789 $\mathrm{mg} / \mathrm{L}$ and $1309 \mathrm{mg} / \mathrm{L}$, approximately $60 \%$ being betacyanins [38]. 
In cranberry juice, a total of 9 anthocyanins were identified (Table 2). Delphinidin 3-O-galactoside was identified in the highest concentration (24.63 mg/100mL), followed by petunidin 3-O-galactoside, delphinidin 3-Oglucoside, and cyanidin3-O-galactoside $(17.28 \mathrm{mg} / 100 \mathrm{~mL}, 16.83 \mathrm{mg} / 100 \mathrm{~mL}$, and $14.68 \mathrm{mg} / 100 \mathrm{~mL}$, respectively). Amongst peonidin derivatives, peonidin $3-O$-galactoside was found in relatively high amount $(8.73 \mathrm{mg} / 100 \mathrm{~mL})$. Previous studies conducted on cranberry extracts reported glycosylated cyanidins and their derivatives (peonidins) as one of the most prevalent anthocyanins $[23,39,40]$.

In terms of sugar moieties attached to aglycone, galactosides were predominant in our samples, followed by glucosides (expect for peonidin and petunidin moieties, where glucosides were not detected) (Table 2). This might be explained with the stability of anthocyanins. When changes in anthocyanin content were evaluated throughout juice processing, it has been demonstrated that anthocyanin stability is determined by the type of sugar attached to aglycones. The order of anthocyanin stability during pasteurization was glucosides $>$ galactosides $>$ arabinosides [41].

Available literature data on the total anthocyanin content of cranberries are heterogeneous. Herein, we detected $99.23 \mathrm{mg} / 100 \mathrm{~mL}$ total anthocyanin. Other researchers reported $18.8 \mathrm{mg} / 100 \mathrm{~mL}$ [42] or $11.36 \mathrm{mg} / \mathrm{L}$ [43] total anthocyanins in cranberry juice and $725 \mathrm{nmol} / \mathrm{g}$ [39] or $117 \mathrm{mg} / \mathrm{g}$ [8] in cranberry extract.

The amount of total identified anthocyanin in pomegranate juice was $70.52 \mathrm{mg} / 100 \mathrm{~mL}$ (Table 2). Mono- and diglucosides of delphinidins, cyanidins, and pelargonidins were identified at different quantity. Highest concentration was detected for cyanidin 3,5-O-diglucoside $(31.25 \mathrm{mg} / 100 \mathrm{~mL}, 44.31 \%$ of the total content). Significantly lower, but similar values were obtained for delphinidin 3,5-O-diglucoside and cyanidin 3-O-glucoside. The total anthocyanins content reported in pomegranate cultivars ranged between $5.56 \mathrm{mg} / 100 \mathrm{~g}$ and $30.11 \mathrm{mg} / 100 \mathrm{~g}$ [44]. Though total anthocyanin content differs significantly among pomegranate varieties, the typical anthocyanin profile of pomegranate juice includes 3-O-glucoside and 3,5-O-diglucosides of delphinidin, cyanidin, and pelargonidin as major components [45-47]. Our findings are in accordance with these reports.

In freshly prepared juices of 15 Iranian pomegranate juices delphinidin 3,5-O-diglucoside, delphinidin 3-O-diglucoside, cyanidin 3,5-O-diglucoside, cyanidin 3-O-glucoside, pelargonidin 3,5-O-diglucoside, and pelargonidin 3-O-glucoside were identified [20]. Very similar results were obtained by Fabroni et al, cyanidin 3,5-O-diglucoside and cyanidin 3-O-glucoside accounting for more than $85 \%$ of total anthocyanins [48]. It is also known that anthocyanin content of pomegranate juice decreases upon thermal treatment. Non-thermal processing methods are used to maximize quality and enhance shelf stability of juices [27]. While the use of pulsed electric field did not alter [49], pasteurization 
processes significantly influenced the anthocyanin content of the pomegranate juice [50-52]. As anthocyanins are also sensible to environmental conditions, juice composition might be changed during storage. The higher the storage temperature, the more pronounced is the anthocyanin degradation and polymeric color formation [53]. Additionally, diglucosides were demonstrated to be more stable than monoglucosides during storage.

Table 2. Betacyanin and anthocyanin content of red juices

\begin{tabular}{|c|c|c|}
\hline Compound & $\begin{array}{l}\text { Concentration* } \\
\left.\text { mg/100mL( }{ }^{*} S D\right)\end{array}$ & $\begin{array}{c}\text { Percentage } \\
\%\end{array}$ \\
\hline \multicolumn{3}{|c|}{ Beetroot juice } \\
\hline Betanin & $281.40 \pm 15.36^{a}$ & 42.88 \\
\hline Isobetanin & $274.40 \pm 16.35^{\mathrm{a}}$ & 41.81 \\
\hline Betanidin & $43.19 \pm 1.25^{b}$ & 6.58 \\
\hline Neo-betanidin-5-glucoside & $57.21 \pm 2.00^{\mathrm{b}}$ & 8.71 \\
\hline Total & 656.21 & 100 \\
\hline \multicolumn{3}{|c|}{ Cranberry juice } \\
\hline Delphinidin 3-O-galactoside & $24.63 \pm 0.94^{a}$ & 24.82 \\
\hline Delphinidin 3-O-glucoside & $16.83 \pm 1.17^{\mathrm{b}}$ & 16.96 \\
\hline Delphinidin 3-O-arabinoside & $5.02 \pm 0.52^{d}$ & 5.05 \\
\hline Cyanidin 3-O-galactoside & $14.68 \pm 0.48^{b}$ & 14.79 \\
\hline Cyanidin 3-O-glucoside & $7.63 \pm 0.82^{c}$ & 7.68 \\
\hline Cyanidin 3-O-arabinoside & $2.98 \pm 0.35^{\mathrm{e}}$ & 3.00 \\
\hline Peonidin-3-O-galactoside & $8.73 \pm 1.19^{c}$ & 8.79 \\
\hline Petunidin 3-O-galactoside & $17.28 \pm 1.31^{b}$ & 17.41 \\
\hline Petunidin 3-O-arabinoside & $1.45 \pm 0.40^{\mathrm{e}}$ & 1.46 \\
\hline Total & 99.23 & 100 \\
\hline \multicolumn{3}{|c|}{ Pomegranate juice } \\
\hline Delphinidin 3,5-O-diglucoside & $19.3 \pm 6.07^{b}$ & 27.36 \\
\hline Delphinidin 3-O-glucoside & $2.35 \pm 0.95^{c}$ & 3.33 \\
\hline Cyanidin 3,5-O-diglucoside & $31.25 \pm 9.82^{a}$ & 44.31 \\
\hline Cyanidin 3-O-glucoside & $12.32 \pm 2.56^{b}$ & 17.47 \\
\hline Pelargonidin 3-O-glucoside & $5.30 \pm 1.10^{c}$ & 7.51 \\
\hline Total & 70.52 & 100 \\
\hline
\end{tabular}

SD, standard deviation. Different letters within a column denote significant differences $(\mathrm{P}<0.05)$. ${ }^{*}$ values are mean of triplicate measurements. 
ANDREA BUNEA, SANDA ANDREI, CRISTINA EL-MAHDI, ALINA CUCERDEAN, FLORIN DUMITRU BORA, ZORITA DIACONEASA, ADELA PINTEA

\section{Ascorbic acid content}

The ascorbic acid concentrations of the analyzed samples are presented in Table 3. Of the yellow fruit juices, higher ascorbic acid contents were observed in carrot samples as compared to apple juice samples. No statistically significant differences were found among carrot samples and apple samples, respectively. However, pasteurization process is likely to negatively influence the ascorbic acid content of carrot juice $(3.52 \mathrm{mg} / 100 \mathrm{~mL}$ in unpasteurized versus $2.40 \mathrm{mg} / 100 \mathrm{~mL}$ in pasteurized sample). Similar trend was not observed in apple juice samples.

Table 3. Ascorbic acid content of juices

\begin{tabular}{lc}
\hline Sample & $\begin{array}{c}\text { Ascorbic acid (士SD) } \\
\mathbf{m g} / \mathbf{1 0 0} \mathbf{m L}\end{array}$ \\
\hline Unfiltered carrot juice & $3.50 \pm 0.86^{\mathrm{b}}$ \\
Pasteurized carrot juice & $2.40 \pm 0.92^{\mathrm{c}}$ \\
Unpasteurized carrot juice & $3.52 \pm 1.05^{\mathrm{b}}$ \\
Commercial apple juice & $2.11 \pm 0.71^{\mathrm{c}}$ \\
Pasteurized apple juice & $2.34 \pm 0.64^{\mathrm{c}}$ \\
Unpasteurized apple juice & $2.81 \pm 0.54^{\mathrm{c}}$ \\
Beetroot juice & $3.52 \pm 0.19^{\mathrm{b}}$ \\
Cranberry juice & $4.57 \pm 0.15^{\mathrm{a}}$ \\
Pomegranate juice & $2.11 \pm 0.08^{\mathrm{c}}$ \\
\hline
\end{tabular}

SD. standard deviation. Different letters within a column denote significant differences $(\mathrm{P}<0.05)$.

Values detected in our study are slightly lower than those reported in literature. In a study analyzing the effect of branching and sonication on the ascorbic acid content of carrot juice, $6.36 \mathrm{mg} / 100 \mathrm{~mL}$ ascorbic acid was reported in untreated juice, $4.31 \mathrm{mg} / 100 \mathrm{~mL}$ in water-blanched and 4.27 $\mathrm{mg} / 100 \mathrm{~mL}$ in acid-blanched juices. These values were significantly increased after submitting carrot juice to sonication $(7.07 \mathrm{mg} / 100 \mathrm{~mL}, 5.37 \mathrm{mg} / 100 \mathrm{~mL}$, and $5.56 \mathrm{mg} / 100 \mathrm{~mL}$, respectively) [30]. Sonication could recover the loss of ascorbic acid by the removal of dissolved oxygen that is a major cause of ascorbic acid degradation. Similarly, ascorbic acid from fresh apple juice was reported at a concentration of $5.27 \mathrm{mg} / 100 \mathrm{~mL}$ [28] and $4.20 \mathrm{mg} / \mathrm{mL}$ [54], which were subsequently increased by sonication up to 6.07 and $5.63 \mathrm{mg} / 100 \mathrm{~mL}$, respectively. It has also been demonstrated, that thermo-sonicated juices retain their ascorbic acid content up to 20 days [34]. In another study conducted at 
Timisoara, remarkably higher amount of ascorbic acid has been reported for fresh-squeezed "Golden auriu" apple juice $(7.02 \mathrm{mg} / 100 \mathrm{~g})$ and beetroot juice (33.84 mg/100g) compared to our results [55].

Amongst red juices, highest ascorbic acid concentration $(4.57 \mathrm{mg} / 100 \mathrm{~mL})$ was obtained in cranberry juice, followed by beetroot $(3.52 \mathrm{mg} / 100 \mathrm{~mL})$ and pomegranate $(2.11 \mathrm{mg} / 100 \mathrm{~mL}$ ) juices (Table 3$)$. In a study conducted by Borges et al, $1107 \mathrm{nmol} / \mathrm{g}$ ascorbic acid has been detected in cranberries [39]. In pomegranate juice prepared from halved fruit, ascorbic acid concentration was $500 \mu \mathrm{g}$ ascorbic acid equivalent/mL [46].

\section{Antioxidant activity}

Highest radical scavenging activity was observed in unprocessed carrot juices (23 mg TE/100g in unfiltered carrot juice, $21 \mathrm{mg}$ TE/ 100g in unpasteurized carrot juice). The loss of activity was significant following pasteurization of the carrot juice (Table 4). Apparently, pasteurization process had no significant effect on the antioxidant capacity of apple juices, though slight decrease was observed in the pasteurized compared to unpasteurized juice.

Table 4. Antioxidant activity of juices

\begin{tabular}{lcc}
\hline Sample & $\begin{array}{c}\text { ORAC } \\
\text { mg TE/100 g (士SD) }\end{array}$ & $\begin{array}{c}\text { Percent of inhibition } \\
(\%)\end{array}$ \\
\hline Unfiltered carrot juice & $23.00 \pm 1.87^{\mathrm{a}}$ & - \\
Pasteurized carrot juice & $18.89 \pm 1.69^{\mathrm{b}}$ & - \\
Unpasteurized carrot juice & $21.00 \pm 2.14^{\mathrm{a}}$ & - \\
Commercial apple juice & $10.00 \pm 0.86^{\mathrm{d}}$ & - \\
Pasteurized apple juice & $13.00 \pm 1.54^{\mathrm{c}}$ & - \\
Unpasteurized apple juice & $14.7 \pm 1.20^{\mathrm{c}}$ & - \\
Beetroot juice & - & $43 \pm 2.71^{\mathrm{a}}$ \\
Cranberry juice & - & $37 \pm 1.89^{\mathrm{b}}$ \\
Pomegranate juice & - & $24 \pm 1.65^{\mathrm{c}}$ \\
\hline
\end{tabular}

SD, standard deviation; TE, Trolox equivalent. Different letters within a column denote significant differences $(P<0.05)$.

According to the data's presented in Tabel $\mathbf{4}$, beetroot juice exhibited the highest inhibitory potential during the first $30 \mathrm{~min}$, followed by cranberry juice and pomegranate juice. 
In the study conducted in the United States, authors detected 6.52 $\mu \mathrm{mol}$ Trolox equivalent (TE)/mL scavenging activity for untreated carrot juice. After 10 days of storage, it has been increased up to $7.07 \mu \mathrm{mol} \mathrm{TE} / \mathrm{mL}$, probably due to the increase in phenolic compounds [34]. The research group led by Zeng reported $32.40 \%$ and $32.87 \%$ DPPH activity for untreated carrot and apple juices, respectively, which were significantly improved by sonication [30,54].

It has been shown that beetroots possess strong antioxidant capacity [56] and this capacity is dependent on the betalain concentration [38]. Guldiken et al have analyzed several home-processed beetroot products and detected a total antioxidant capacity of $110 \mathrm{mg}$ TE/ $100 \mathrm{~g}$ beetroot juice using DPPH assay, significantly lower than that measured for fresh, unprocessed beetroot (137 mg TE/100g) [35].

Juice processing was found to influence significantly the free radical scavenging activity of cranberry [24]. Is has been postulated, that anthocyanins are the major contributor to the antioxidant activity in cranberries, contributing $39 \%$ of the total antioxidant capacity. Ascorbic acid was responsible for $22.6 \%$ of antioxidant activity [39]. A strong negative correlation $(r=-0.92)$ was found between anthocyanin level and relative antioxidant potential in cranberries, while ascorbic acid content was positively correlated $(r=0.84)$ [40]. On the other hand, correlation analysis indicated close association between total phenolic content and antioxidant activity [57].

In case of pomegranate, linear relationship was observed between radical scavenging potential and total monomeric anthocyanins, suggesting that these compounds contributed greatly to the antioxidant capacity in pasteurized pomegranate fruit [58]. In a study comparing eight innovative fruit beverages, pomegranate juice presented the highest DPPH radical scavenging activity (539.87 g gallic acid equivalent $/ \mathrm{mL})$, total carotenoids $(3.18 \mu \mathrm{g} \beta$ carotene equivalent $/ \mathrm{mL})$, and total phenolic content $(3766.33 \mu \mathrm{g} / \mathrm{mL})$ even after 20 days of storage at $4^{\circ} \mathrm{C}$. Interestingly, antioxidant activity increased during storage [19]. This might be explained by the susceptibility of polyphenols to polymerization reaction [59]. As Iran controls approximately $47 \%$ of the world pomegranate production, the Iranian pomegranate juice has been the subject of numerous studies. However, miscellaneous data were reported on the antioxidant potential of these varieties. While Derakhshan et al reported 9-10\% scavenging potential [60], significantly higher values (15.59-40.72\%) have also been reported [44]. Pomegranate fractions used for juices could also determine the antioxidant activity of juice. A study conducted by Mphahlele et al demonstrated that halved fruit juice has the highest antioxidant activity as compared to arils, arils and seeds, and whole fruit [46]. 


\section{CONCLUSIONS}

Although we had limited information about the source of the fruits and vegetables and post-harvest regimen, the present analysis revealed that the phytochemical composition and quality of marketed beverages are fairly different and strongly related to processing techniques. All carrots juices analyzed herein contains approximately 2 -fold higher carotenoids than apple juices. Betanin and isobetanin were identified as the major betacyanins in beetroot juice, while the anthocyanin profile of cranberry and pomegranate juices consists of 3-O-glucosides, 3-O-galactosides, and 3-O-arabinosides of malvidin, delphinidin, cyanidin, and petunidin. Ascorbic acid content ranged between $2.11 \mathrm{mg} / 100 \mathrm{~mL}$ (commercial apple juice and beetroot juice) and $4.57 \mathrm{mg} / 100 \mathrm{~mL}$ (cranberry juice). DPPH scavenging capacity was highest in the unprocessed carrot juice and lowest in Commercial apple juice. Amongst red juices, beetroot juice exhibited a percentage of inhibition higher than cranberry or pomegranate juices.

\section{EXPERIMENTAL SECTION}

Pasteurized and unpasteurized carrot and apple juices were obtained from a local producer. All other juices were purchased from the local market.

Methanol, ethyl acetate, petroleum ether, diethyl ether, triethylamine, sodium chloride, anhydrous sodium sulphate were purchased from Sigma Chemical Co. The purity of carotenoid standards (98\% for $\beta$-cryptoxanthin, $96 \%$ for $\beta$-carotene, $97.5 \%$ for lutein) was estimated by UV-VIS spectra and by an individual HPLC. Solvents used for carotenoid analysis (ethyl acetate, ethanol, hexane) were purchased from Merck.

\section{Carotenoid separation, identification, and statistical methods}

Carotenoids were extracted from $15 \mathrm{ml}$ juice with a mixture of ethanol/ ethyl acetate/hexane $(\phi r=1: 0.5: 0.5)$ containing butylated hydroxytoluene as anti-oxidant, following the procedure described by [61]. The sample was centrifuged, and extraction was repeated until the residue became colorless. The extracts were combined and partitioned in a separation funnel, successively with water, diethyl ether, and saturated saline solution. The ether phase was evaporated to dryness at $35^{\circ} \mathrm{C}$ under diminished pressure using a rotary evaporator. The samples were kept under nitrogen, at $-20^{\circ} \mathrm{C}$ until further use. A proportion of the oleoresin obtained was dissolved in diethyl ether and saponified with $30 \%$ methanolic $\mathrm{KOH}$ at room temperature in the 
dark. For the removal of soaps and alkalis, the solution was washed several times with a sodium chloride saturated solution and distilled water. The organic layer containing carotenoids was dried with anhydrous sodium sulphate and evaporated to dryness. The samples were kept under nitrogen, at $-20^{\circ} \mathrm{C}$ until further utilization. HPLC-PDA was performed using a system of Shimadzu LC20 AT with Waters 990 PDA detector, Kontron pumps and controller, and a reversed phase C18 column Hibar 250-4 Lichrosorb C18 (250 x 4,6 mm), 5 $\mu \mathrm{m}$. The mobile phases used were acetonitrile/water $(\phi r=9: 1)$ with $0.25 \%$ of triethylamine $(A)$, and ethyl acetate with $0.25 \%$ of triethylamine (B). The gradient started with $15 \%$ of $B$ at 0 min and increased to $50 \%$ of $B$ at $16 \mathrm{~min}$. The program continued isocratically with $50 \%$ of $B$ up to $30 \mathrm{~min}$. The flow-rate was $1 \mathrm{~mL} \mathrm{~min}{ }^{-1}$. The chromatograms were monitored at $450 \mathrm{~nm}$.

\section{Anthocyanins extraction and determination}

Ten $\mathrm{ml}$ of juice was centrifuged at $3500 \mathrm{rpm}$ for $10 \mathrm{~min}$, filtered and directly injected to the HPLC. Analyses were performed on a Shimadzu HPLC system equipped with a binary pump delivery system LC-20 AT (Prominence), a degasser DGU-20 A3 (Prominence), diode-array SPD-M20 A UV-VIS detector and a Luna Phenomenex C18 column $(5 \mu \mathrm{m}, 25 \mathrm{~cm} \times 4.6$ $\mathrm{mm}$ ) was used. The mobile phase consisted in: solvent $A$ - formic acid (4.5\%) in bidistilled water and solvent $\mathrm{B}$ - acetonitrile. The gradient elution system was: $10 \%$ B, 0-9 min; $12 \%$ B, 9-17 min; 25\% B 17-30 min; 90\% B, 30-50 min; $10 \% \mathrm{~B}, 50-55 \mathrm{~min}$. The flow rate was $0.8 \mathrm{ml} / \mathrm{min}$ and the analyses were performed at $35^{\circ} \mathrm{C}$. The chromatograms were monitored at 520 and $580 \mathrm{~nm}$ respectively for betalains.

\section{Ascorbic acid determination}

Ascorbic acid content was quantitatively determined according to the titrimetric method described by Moldovan et al., based on the oxidation of ascorbic acid with iodine [62].

\section{Antioxidant activity}

The antioxidant activity of juice samples was measured and calculated by the oxygen radical absorbance capacity assay, as described previously [64]. ORAC values were expressed as $\mathrm{mg}$ TE/100 $\mathrm{g}$ reported on fresh weight. The 2,2-Diphenyl-1-picrylhydrazyl (DPPH) radical is one of the few stable organic nitrogen radicals, which bears a deep purple color. $50 \mu \mathrm{L}$ of extracts 
were added with $1.0 \mathrm{~mL}$ of $0.4 \mathrm{mM}$ methanolic - DPPH and brought up with methanol to $5.0 \mathrm{~mL}$. The mixture was shaken vigorously using a vortex and left to stand for $15 \mathrm{~min}$, at room temperature, in the dark. The scavenging effect on the DPPH radical was read using a spectrophotometer at $517 \mathrm{~nm}$. The radical scavenging activity was expressed using the following equation: percentage (\%) of DPPH radical scavenging:

$$
\% D P P H \cdot \text { scavenging activity }=\left(1-\left[\frac{\text { Asample }}{\text { Acontrol } t=0)}\right]\right) 100
$$

where: Asample - Absorbtion of test extract solution ( $\mathrm{t}=15 \mathrm{~min})$ Acontrol $\mathrm{t}=\mathrm{o}$ Absorbtion of blank sample $(\mathrm{t}=\mathrm{o} \mathrm{min})$

DPPH solution was used as control.

\section{ACKNOWLEDGMENTS}

This project is funded by the Ministry of Research and Innovation through Program 1 - Development of the National Research and Development System, Subprogram 1.2 - Institutional Performance - Projects for Financing the Excellence in CDI, Contract no.37PFE/06.11.2018.

\section{REFERENCES}

1. M. Rodriguez-Concepcion, J. Avalos, M.L. Bonet, A. Boronat, L. GomezGomez, D. Hornero-Mendez, M.C. Limon, A.J. Meléndez-Martínez, B. Olmedilla-Alonso, A. Palou, J. Ribot, M.J. Rodrigo, L. Zacarias, C. Zhu. Progress in Lipid Research, 2018, 70, 62.

2. R.K. Saini, S.H. Nile, S.W. Park. Food Research International, 2015, 76, 735.

3. P.S. Bernstein, F. Khachik, L.S. Carvalho, G.J. Muir, D.Y. Zhao, N.B. Katz. Experimental eye research, 2001, 72, 215.

4. N. Chhikara, K. Kushwaha, P. Sharma, Y. Gat, A. Panghal. Food Chemistry, 2019, 272, 192.

5. A. Cassidy. Molecular Aspects of Medicine, 2018, 61, 76.

6. L. Xie, H. Su, C. Sun, X. Zheng, W. Chen. Trends in Food Science \& Technology, 2018, 72, 13.

7. M.J. Kruger, N. Davies, K.H. Myburgh, S. Lecour. Food Research International, 2014, 59, 41. 
ANDREA BUNEA, SANDA ANDREI, CRISTINA EL-MAHDI, ALINA CUCERDEAN, FLORIN DUMITRU BORA, ZORITA DIACONEASA, ADELA PINTEA

8. R. Puupponen-Pimia, L. Nohynek, C. Meier, M. Kahkonen, M. Heinonen, A. Hopia, K.M. Oksman-Caldentey. Journal of Applied Microbiology, 2001, 90, 494.

9. S. Kurl, T.P. Tuomainen, J.A. Laukkanen, K. Nyyssönen, T. Lakka, J. Sivenius, J.T. Salonen. Stroke, 2002, 33, 1568.

10. N. Shenoy, E. Creagan, T. Witzig, M. Levine. Cancer Cell, 2018, 34, 700.

11. S.K. Osganian, M.J. Stampfer, E. Rimm, D. Spiegelman, F.B. Hu, J.E. Manson, W.C. Willett. Journal of the American College of Cardiology, 2003, 42, 246.

12. T. Ritz, C.A. Werchan, J.L. Kroll, D. Rosenfield. Physiology \& Behavior, 2019, 202, 45.

13. S. Caillet, J. Côté, G. Doyon, J.F. Sylvain, M. Lacroix. Food Research International, 2011, 44, 1408.

14. Z. Esmaeilinezhad, S. Babajafari, Z. Sohrabi, M. H. Eskandari, S. Amooee, R. Barati-Boldaji. Nutrition, Metabolism and Cardiovascular Diseases, 2019, 29, 201.

15. A. Sahebkar, C. Ferri, P. Giorgini, S. Bo, P. Nachtigal, D. Grassi. Pharmacological Research, 2017, 115, 149.

16. G. Sohrab, H. Roshan, S. Ebrahimof, O. Nikpayam, G. Sotoudeh, F. Siasi. Clinical Nutrition ESPEN, 2019, 29, 30.

17. C.M. Matthaiou, N. Goutzourelas, D. Stagos, E. Sarafoglou, A. Jamurtas, S.D. Koulocheri, S.A. Haroutounian, A.M. Tsatsakis, D. Kouretas. Food and Chemical Toxicology, 2014, 73, 1.

18. M. Karimi, R. Sadeghi, J. Kokini. Trends in Food Science \& Technology, 2017, 69, 59.

19. C. Castro-López, E.J. Sánchez-Alejo, S. Saucedo-Pompa, R. Rojas, J. ArandaRuiz, G.C.G. Martínez-Avila. Heliyon, 2016, 2, e00152.

20. H. Alighourchi. European Food Research \& Technology, 2008, v. 227, pp. 881.

21. M. Zielinska, D. Zielinska. LWT-Food Science and Technology, 2019, 104, 202.

22. F. Weber, L.R. Larsen. Food Research International, 2017, 100, 354.

23. G.M. Cătunescu, A.M. Rotar, C.R. Pop, Z. Diaconeasa, F. Bunghez, M.-I. Socaciu, C.A. Semeniuc. LWT-Food Science and Technology, 2019, 102, 385.

24. J. Côté, S. Caillet, G. Doyon, D. Dussault, S. Salmieri, G. Lorenzo, J. F. Sylvain, M. Lacroix. Food Research International, 2011, 44, 2907.

25. M. Marx, M. Stuparic, A. Schieber, R. Carle. Food Chemistry, 2003, 83, 609.

26. F. Chemat, H. Zill e, M. K. Khan. Ultrasonics Sonochemistry, 2011, 18, 813.

27. P. Putnik, Ž. Kresoja, T. Bosiljkov, A. Režek Jambrak, F.J. Barba, J.M. Lorenzo, S. Roohinejad, D. Granato, I. Žuntar, D. Bursać Kovačević. Food Chemistry, 2019, 279, 150.

28. M. Abid, S. Jabbar, B. Hu, M.M. Hashim, T. Wu, S. Lei, M.A. Khan, X. Zeng. Ultrasonics Sonochemistry, 2014, 21, 984.

29. M. Abid, S. Jabbar, T. Wu, M.M. Hashim, B. Hu, S. Lei, X. Zeng. Ultrasonics Sonochemistry, 2014, 21, 93.

30. S. Jabbar, M. Abid, T. Wu, M.M. Hashim, B. Hu, S. Lei, X. Zhu, X. Zeng. Int J Food Science \& Nutrition, 2014, 65, 28.

31. L.Q. Zepka, A.Z. Mercadante. Food Chemistry, 2009, 117, 28.

32. M. Marx, A. Schieber, R. Carle. Food Chemistry, 2000, 70, 403. 
33. B.H. Chen, H.Y. Peng, H.E. Chen. Journal of Agricultural and Food Chemistry, 1995, 43, 1912.

34. H.E. Martínez-Flores, M.G. Garnica-Romo, D. Bermúdez-Aguirre, P.R. Pokhrel, G.V. Barbosa-Cánovas. Food Chemistry, 2015, 172, 650.

35. B. Guldiken, G. Toydemir, K. Nur Memis, S. Okur, D. Boyacioglu, E. Capanoglu. International Journal of Molecular Sciences, 2016, 17.

36. F.C. Stintzing, J. Trichterborn, R. Carle. Food Chemistry, 2006, 94, 296.

37. K.M. Herbach, F.C. Stintzing, R. Carle. Journal of Food Science, 2004, 69, C491.

38. J. Wruss, G. Waldenberger, S. Huemer, P. Uygun, P. Lanzerstorfer, U. Müller, O. Höglinger, J. Weghuber. Journal of Food Composition and Analysis, 2015, 42, 46.

39. G. Borges, A. Degeneve, W. Mullen, A. Crozier. Journal of Agricultural and Food Chemistry, 2010, 58, 3901.

40. P.N. Brown, C.E. Turi, P.R. Shipley, S.J. Murch. Planta Medica, 2012, 78, 630.

41. B.L. White, L.R. Howard, R.L. Prior. Journal of Agricultural Food Chemistry, 2011, 59, 4692.

42. J.D. Wightman, R.E. Wrolstad. Journal of Food Science, 1995, 60, 862.

43. I.M. Caminiti, F. Noci, A. Muñoz, P. Whyte, D.J. Morgan, D.A. Cronin, J.G. Lyng. Food Chemistry, 2011, 124, 1387.

44. A. Tehranifar, M. Zarei, Z. Nemati, B. Esfandiyari, M. R. Vazifeshenas. Scientia Horticulturae, 2010, 126, 180.

45. G. Borges, A. Crozier. Food Chemistry, 2012, 135, 1863.

46. R.R. Mphahlele, O.A. Fawole, L.M. Mokwena, U.L. Opara. South African Journal of Botany, 2016, 103, 135.

47. U.A. Fischer, R. Carle, D.R. Kammerer. Food Chemistry, 2011, 127, 807.

48. S. Fabroni, G. Ballistreri, M. Amenta, F.V. Romeo, P. Rapisarda. Journal of Scince Food Agriculture, 2016, 96, 4713.

49. M. Guo. Food and Bioprocess Technology, 2013, v. 6, 2013 v. 6 no.11.

50. U.A. Fischer, R. Carle, D.R. Kammerer. Food Chemistry, 2013, 138, 1800.

51. P. Mena, S. Vegara, N. Martí, C. García-Viguera, D. Saura, M. Valero. Food Chemistry, 2013, 141, 2122.

52. Ö. Turfan, M. Türkyılmaz, O. Yemiş, M. Özkan. Food Chemistry, 2011, 129, 1644.

53. Ö. Turfan, M. Türkyilmaz, O. Yemiş, M. Özkan. Journal of Food Quality, 2012, $35,272$.

54. M. Abid, S. Jabbar, T. Wu, M.M. Hashim, B. Hu, S. Lei, X. Zhang, X. Zeng. Ultrasonics Sonochemistry, 2013, 20, 1182.

55. D.G. Dumbravă, N.G. Hădărugă, C. Moldovan, D.N. Raba, M.V. Popa, B. Rădoi. Journal of Agroalimentary Processes and Technologies, 2011, 17, 163.

56. P.C. Wootton-Beard, L. Ryan. Journal of Functional Foods, 2011, 3, 329.

57. M. Fidelis, J.S. Santos, A.L.K. Coelho, O.Y. Rodionova, A. Pomerantsev, D. Granato. Food Control, 2017, 73, 796.

58. S. Vegara, P. Mena, N. Martí, D. Saura, M. Valero. Food Chemistry, 2013, 141, 1630. 
ANDREA BUNEA, SANDA ANDREI, CRISTINA EL-MAHDI, ALINA CUCERDEAN, FLORIN DUMITRU BORA, ZORITA DIACONEASA, ADELA PINTEA

59. M. Pinelo, L. Manzocco, M.J. Nuñez, M.C. Nicoli. Journal of Agricultural and Food Chemistry, 2004, 52, 1177.

60. Z. Derakhshan, M. Ferrante, M. Tadi, F. Ansari, A. Heydari, M. S. Hosseini, G.O. Conti, E.K. Sadrabad. Food and Chemical Toxicology, 2018, 114, 108.

61. D.E. Breithaupt, W. Schwack. European Food Research and Technology, 2000, 211, 52.

62. P. Moldovan, M.I. Toşa, D. Leţ, C. Majdik, C. Paizs, F.D. Irimie. Aplicaţii pentru laboratorul de biochimie, Editura Napoca Star, 2006, p. 110-115.

63. D. Huang, B. Ou, M. Hampsch-Woodill, J.A. Flanagan, R.L. Prior. Journal of Agricultural and Food Chemistry, 2002, 50(16):4437. 